\title{
Los paisajes perdidos de Vicente Araguas
}

\author{
Verónica Palomares Maíllo \\ Universidad Complutense \\ veromares@hotmail.com
}

Recibido: junio de 2012 Aceptado: julio de 2012

\begin{abstract}
Resumen: El grupo Bilbao ha logrado convertirse en un importante movimiento de recepción y difusión de la cultura gallega en Madrid. La aportación del poeta Vicente Araguas a esta labor de promoción se ha consolidado, no solo desde su papel como uno de los fundadores del grupo, sino también desde su escritura, en la que la lengua y la cultura gallegas están siempre presentes. Este artículo destaca la importancia del paisaje como uno de los elementos poéticos más importantes que vinculan al poeta con su tierra.
\end{abstract}

Palabras clave: Vicente Araguas, Grupo Bilbao, paisaje, Galicia, identidad y cultura.

\begin{abstract}
The Bilbao group has become an important movement that has welcomed and helped to develop the Galician culture in Madrid. Since its origins, the contribution of Vicente Araguas to the group's work has been crucial, not only because of his role as one of the founders of the group, but also due to his own writing in which the Galician culture and language are always present. The following article highlights Araguas's use of landscape where he effectively unites his poetry to his native land.
\end{abstract}

Keywords: Vicente Araguas, Bilbao Group, Landscape, Galicia, identity and culture.

Cuando la lengua materna se convierte, lejos de su lugar de origen, en una lengua extranjera y, a pesar de ello, el hablante desea seguir utilizándola como medio de expresión artística, se hace necesario enfrentarse a una doble problemática. Por un lado, surge la necesidad de salvar la distancia cultural que media entre la obra literaria producida fuera del ámbito lingüístico al que pertenece y la comunidad de hablantes que no comparten la lengua en la que el escritor se expresa. Por otro lado, la lejanía física entre el lugar de producción literaria y el lugar de origen del autor supone otra barrera que amenaza con la exclusión y 
la marginalidad. Lograr dar a conocer la producción literaria de una comunidad de escritores gallegos que viven y escriben lejos de Galicia se presenta, en definitiva, como una tarea de extraordinaria dificultad. En el caso del poeta Vicente Araguas, el enfrentamiento contra la distancia — cultural y física-, se plantea desde la escritura y la participación activa en distintas iniciativas culturales para la difusión de la literatura gallega en Madrid.

Araguas escribe en gallego y sobre Galicia para estar permanentemente en ella. Todos los vínculos culturales y afectivos que surgen en su escritura se condensan en un motivo poético constante: el paisaje. El título de su primer poemario publicado - Paisaxe de Glasgow (1978) - , ya muestra la importancia del paisaje como el ámbito poético en el que recoger las vivencias e impresiones de un lugar importante para el autor. De este modo, el paisaje supone la forma más eficaz de reconstruir la trayectoria vital y poética de Araguas, una manera de conocer cómo es la Galicia que habita el poeta cuando vive lejos de ella, ya que el paisaje contiene, en definitiva, la identidad y el conocimiento del mundo vivido.

En la obra de Araguas encontramos, por un lado, el paisaje exterior, estático, contemplado hasta hacerse memoria. Por otro, el paisaje vivo e interior que se alimenta del tiempo y las pasiones que han construido al poeta. Ambos paisajes definen al hombre y el lugar que habita.

El paisaje atrae y condensa en el poema todos los elementos necesarios para el reconocimiento de un espacio del que es fácil sentirse expulsado por el tiempo y la distancia y al que se pertenece débilmente en una ausencia prolongada. Cuando alguien debe alejarse de un lugar, solo puede regresar a él en el recuerdo, en la mirada y en los nuevos lugares habitados. Ese sentido de apropiación poética expresa una derrota, la permanencia imposible en los espacios que reclamamos como nuestros y de los que, tarde o temprano, desaparecemos. La identidad y el vínculo que nos une a los lugares amados se debilitan en cada despedida. El regreso, poco a poco, se vuelve inseguro. A veces, se regresa para descubrir que no es posible recobrar el lugar abandonado, que algo ha cambiado o ha sido reemplazado. Cuando alguien debe partir de nuevo, no puede saber de qué lugares se has despedido sin saberlo. Descubrir esa ausencia es herir poco a poco la tierra a la que se vuelve. Es entonces cuando empiezan a coexistir dos lugares al mismo tiempo: el primero, al que solo se puede regresar desde la memoria, y el nuevo lugar surgido del cambio, que cubre con su nuevo rostro el antiguo espacio conocido. De ahí la importancia del poema, ya que es el único espacio que conserva intacto y vivo el primer escenario de nuestra existencia. El poema se convierte en una forma de regreso y, en última instancia, en un lugar. De este modo el poeta es Xuvia-Neda y en su interior el río de la infancia no se detiene, pero también es la niebla y el frío de Escocia, el ruido y el calor de Madrid. Eso es Araguas y eso somos todos: aquello que logramos robarle al paisaje que amamos.

El primer paisaje poético que encontramos en su obra es el de Escocia. Los primeros escenarios y los elementos más importantes que lo definen guardan cierta similitud con el paisaje de Galicia: las amistades, la música y el mar. La melancolía, elemento constante en su poesía, ya que en la obra de Vicente Ara- 
guas no hay memoria si no hay melancolía, aparece en la evocación de estos primeros paisajes.

Años más tarde, en algunos de sus otros poemarios, regresamos a Neda, a la infancia, y allí el paisaje se vuelve más nítido. Los elementos descritos nombran con exactitud el lugar recordado: el Camiño Velho, el Cine Principal, el Empedrón, Ancos, el río, los juegos... El primer paisaje es el más decisivo, porque se convertirá en el lugar del regreso. La primera Galicia, la vivida en la infancia, supone el primer y único mundo posible para un niño. La impronta que dejan los primeros escenarios vitales no desaparecerá nunca del poeta. De esta forma, la evocación del pasado es siempre un lugar en el que recuperar un entramado de voces, imágenes y sensaciones que la memoria intenta ordenar y el poema intenta retener.

Y el amor, siempre el amor, en todas partes, camino constante que recorre todos los escenarios y paisajes, a veces asaltados por la presencia abrupta de la muerte. Una elegía, - el «poema XV» de Veinticuatro maneras de querer a Brian - reúne otros elementos importante del paisaje de Araguas, que se suman a los citados anteriormente: las largas conversaciones, la noche, los libros y la tristeza - siempre unida a la belleza y a la ternura-, la amistad y el paso del tiempo. Todo lo que nombra Araguas se transforma en paisaje, en un único paisaje que lleva hacia su interior todos los lugares que el poeta ha habitado. Por este motivo, es interesante contemplar el tejido que cubre el espacio poético de su obra, los grandes escenarios y los pequeños rincones, los espacios abandonados y revisitados, los lugares que cualquier persona necesita tener para saber quién es y qué forma tiene lo que ha vivido.

El universo de un hombre no se diferencia en exceso del resto. Todos guardamos lo mismo en nuestros paisajes particulares: aquello que nos obliga a atarnos para siempre a un lugar que nos identifica y que nos explica la belleza del mundo. Todos somos los lugares que amamos. Esa es nuestra verdadera identidad. Hay un significado mucho más interesante del concepto de nacionalidad, que trasciende el hecho accidental del nacimiento, incluso el más permanente de la residencia. Uno es gallego, evidentemente, si ha nacido en Galicia. Pero también lo es aquel que se siente gallego cuando escucha la lengua y quiere aprenderla, cuando desea poder escribir y expresarse también en las palabras del otro. Alguien es gallego cuando se reconoce en la literatura, en los paisajes o en el calor de la gente de Galicia. Hay gallegos que han nacido en Galicia y gallegos que han nacido en el conocimiento y admiración de Galicia. Aunque hayan llegado más tarde, pertenecen también al mismo lugar. Nacer o vivir fuera de Galicia no te expulsa de ella. De hecho, se puede vivir más intensamente un lugar cuando se está lejos de él. Aquel que vive en Galicia no necesita pensar en Galicia porque se encuentra en ella o, al menos, no necesita pensarla de la misma manera. Cuando se está lejos, el regreso se hace constante y se buscan, cada día, todas las formas posibles de llegar, de mantenerse en la misma línea temporal. Y este vínculo deseado y luchado cada día hace más fuerte la unión.

Sin embargo, el tiempo erosiona hasta los vínculos más fuertes. Una parte de la Galicia vivida se va transformando inevitablemente. En la distancia, el poeta y su tierra evolucionan y cambian lentamente. Surge entonces la necesidad de 
preguntarse si el tiempo modifica a los dos de la misma manera. Si el lugar nos espera, intacto, o nos traiciona transformándose lejos de nosotros, borrando partes que nos pertenecían, superponiendo otros lugares que nos devuelven una imagen irreconocible de nosotros mismos, obligándonos a ser un poco extraños, un poco extranjeros en la propia tierra.

La mirada del poeta realiza el esfuerzo del reconocimiento y la memoria precaria se somete a la pérdida, a la desfiguración, a la imagen idealizada que se extiende desde la distancia y no siempre puede ser cobrada. La mirada del porvenir, la espera más incierta y lejana de todas, no puede prometer la seguridad del regreso. Es difícil, y a veces doloroso, intentar sobrevivir en un lugar en el que no se puede permanecer de manera física y continua. Por eso, lejos de la tierra a la que sabemos que pertenecemos, nos esforzamos por mantenernos, por reivindicar nuestra permanencia, el estado intacto de nuestro vínculo, nuestro regreso constante. Recordar para reconstruir y regresar se hace necesario. Hay diversas formas de reconstrucción y la escritura es, sin duda, una de ellas, al igual que la búsqueda de las señas de identidad que sobreviven fuera, como la lengua, la cultura y las personas que forman parte de esa tierra lejana. Esa búsqueda solo sobrevive con el esfuerzo de personas que saben reunir y reconocer los vínculos esenciales. La creación del grupo Bilbao es un ejemplo de cómo rescatar y reconstruir una parte de tierra a la deriva y constatar cómo puede sobrevivir Galicia en la distancia y en el tiempo. De cuántas formas podemos llevar un lugar con nosotros y cómo reconocerlo al reunir distintas miradas.

Fue precisamente Vicente Araguas quien bautizó el grupo con el nombre del café donde empezaron a reunirse sus integrantes en Noviembre de 1996. En un artículo que Xavier Frías-Conde le dedica en los Cuadernos del Ateneo, reconoce en este grupo: «no una generación, sino un punto de encuentro entre personas que viven una literatura y una lengua común lejos del suelo originario de esa lengua en la que sienten, en la que gustan de expresarse» (2007: 72) .

En el artículo anteriormente citado, Xavier Frías menciona además la palabra mestizaje, concepto importante que trasciende la noción de pureza, condenada muchas veces al empobrecimiento cultural, en una defensa inútil de cualquier contaminación exterior. La mezcla interior de voces, de lugares y culturas es una forma de destacar lo que nos diferencia y lo que nos une. En el grupo Bilbao se encuentran autores que han escrito siempre en gallego, poetas que han adoptado finalmente el gallego como lengua de expresión y personas que han aprendido la lengua para poder expresarse también en ella. Estas circunstancias demuestran que en la creación literaria el lugar de procedencia no es tan determinante como la necesidad de elegir libremente las lenguas y culturas que resulten más atrayentes

Si el Grupo Bilbao no puede considerarse una generación de escritores, sino un lugar de encuentro, un punto de referencia para la lengua y la literatura de Galicia que vive y crea fuera de ella, es importante mencionar a sus referentes más visibles, entre los que cabe destacar a Vicente Araguas y no solo por ser uno de los vínculos más fuertes de este movimiento poético gallego en Madrid, tal como recuerda Xavier Frías, sino por toda su labor de recepción y promoción de nuevas voces literarias junto a escritores más consolidados. Durante varios 
años (2006-2009), Araguas fue el encargado de conducir encuentros de escritores en la Casa de Galicia de Madrid. Gracias a la labor de muchos autores y personas interesadas en la cultura y la poesía gallegas, que han sabido abrir un lugar para enriquecer las opciones culturales de Madrid, es posible conocer o revivirsegún el caso- la tierra y la cultura gallegas.

Sin embargo, lo pequeño no siempre encuentra con facilidad su espacio. Por ello es necesario destacar también el valor y la importancia de aquellos que, gallegos o no, han querido acercarse a una lengua y una literatura pequeñas. Este interés se enfrenta también a múltiples barreras, sobre todo por el peso abrumador de la literatura oficial, que siempre goza de una mayor visibilidad, aunque su mérito poco tenga que ver en ocasiones con su calidad, sino con circunstancias extraliterarias. Otra de las grandes dificultades es encontrar textos y espacios dedicados a lenguas minoritarias o personas que compartan el mismo interés, cuando lo normal es enfrentarse a la incomprensión del resto. Pese a todo ello, este público, quizá más entregado que otro más masivo y por ello también más pasivo y dormido, se mantiene siempre atento al más mínimo faro, a la primera llamada que brinde una oportunidad de encuentro. De ahí la importancia de iniciativas culturales, de la existencia de grupos y actividades que alimenten literaturas poco atendidas.

Xavier Frías lamenta en el artículo antes citado la dificultad de aproximarse a la literatura gallega, aún más si ese acercamiento debe hacerse desde cientos de kilómetros. De esta dificultad sabe mucho Vicente Araguas, quien ha sido capaz de alzar en Madrid, una ciudad que se presta a diluir fácilmente las huellas del exterior, un lugar donde salvar una frágil presencia, la de un género literario minoritario hablado en una lengua exiliada del hogar materno. La inmensidad de las minorías no se cifra en su cualidad numérica, sino en la intensidad y la entrega incondicional que alcanzan sus seguidores, por escasos que puedan parecer. Por ello resulta esencial crear un punto de encuentro donde acoger una comunidad oculta por la inmensidad de la capital.

Otra dificultad que hay que añadir a la existencia de la poesía gallega en Madrid es el peligro de la endogamia. El intento de reunir y difundir la cultura de un grupo puede terminar por condenarlo a encerrarse en sí mismo, sin posibilidad de trascender el pequeño espacio que ocupa. Sin embargo, la aportación de Vicente Araguas para la difusión de la poesía gallega siempre ha sabido salvar esta barrera. Con el tiempo, las estaciones poéticas organizadas en la Casa de Galicia sirvieron de encuentro para poetas gallegos, castellanos y portugueses. La mezcla de voces, de literaturas y autores ilustra muy bien que la mejor manera de conocer y conocerse es en el encuentro con el otro. Y esta circunstancia no solo se da en los encuentros del Grupo Bilbao o en las estaciones poéticas organizadas. Otra forma de llegar a Galicia lejos de ella es en los libros donde se ha retratado su recuerdo. Y en el caso de Araguas, no solo surge en sus libros la silueta de la Galicia conocida y añorada, sino también los lugares que, como ella, viven dentro del poeta.

Hay tres poemas de Vicente Araguas que condensan el constante paisaje que tiene en Galicia su lugar de partida. En ellos podemos ver también el modo en que Galicia desborda poco a poco sus fronteras hasta alcanzar los lugares donde 
ha llegado el poeta. El primero de ellos, «A rúa que era miña», del libro $O$ Gato Branco:
A rúa que era miña
No seu sorriso asoma
a silueta
de dous xeránios
e o pan e o chocolate
riba da mesa.
A miña rúa
nun flash-back
de domingos
e traxe novo.
Rúa de festa.
O renxer dos tranvías
cando viraban,
un chío de gorrións
e de merendas.
A rúa que foi miña:
bandeiras na terraza,
unha foto ao minuto,
gaitas na néboa.
A miña rúa:
un cheiro de xazmíns, unha verbena.

En este poema, se posan todos los cimientos de un paisaje que el tiempo no puede tocar. La infancia sobrevive en la memoria sensitiva y construye un paisaje capaz de conservar el color, los sonidos y el sabor que alertaron al niño, por primera vez, de la belleza del mundo.

El segundo texto es el poema «XXIII», del libro Paisaxe de Glasgow,

XXIII

Jane Fonda Manuel Antonio

rimbaud vivaldi krivine

morente behan viglietti

gómez brassens e mclean

sillitoe d.h. lawrence

faulkner mallarme ferrín

cassius clay thelonius monk

morris raimon kropotkin

saura daniel goytisolo

foucellas raúl bailarín 


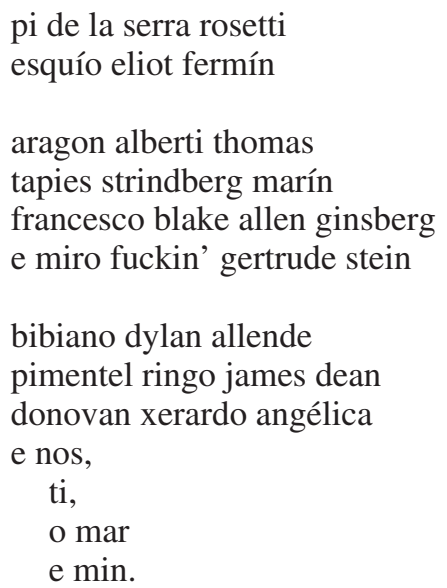

Si seguimos el viaje cultural que Araguas describe en este poema y cruzamos todos los textos y las ideas que contiene, procedentes de autores tan diversos que se expresan en lenguas tan distintas entre sí, llegamos al mismo destino que el poeta ha seguido, la primera y última frontera, Galicia. Y el concepto de cultura del que antes se ha hablado es, precisamente, este recorrido que propone el poeta y que anula la importancia del lugar o de la lengua elegida para expresarse, dado que nos nutrimos constantemente de diferentes culturas y son diversas las lenguas que nos habitan y que sostienen nuestra propia lengua. Por ello, lo verdaderamente trascendente no es la lengua o el lugar de origen, sino las lenguas y lugares que elegimos conocer y vivir.

El último poema que construye los paisajes esenciales de Araguas pertenece a Xuvia Revisitada:

\section{Epitafio}

(na tomba que me agarda en Santa María de Neda)
Amei, vivín, soñei, non fixen outra cousa que camiñar a modo coa paixón do que busca no mundo a beleza. Nada máis natural. Nacín en Neda.

Esta es la Galicia de Vicente Araguas: las calles de Xuvia, las canciones y libros mil veces visitados y la pasión, la única vía que permite la vivencia plena de la belleza. Todos los lugares que el poeta conoce y entrega a su tierra enriquecen y fortalecen la identidad de ambos. Este concepto de pertenencia que convierte otras culturas y países en diferentes versiones del lugar de origen sustenta toda la 
obra poética de Araguas y forma el verdadero paisaje que el poeta nos describe una y otra vez, de tantas formas.

Amor, literatura, infancia y belleza, son, en definitiva, los lugares donde poder transportar la tierra amada, las últimas patrias que abandonaremos.

\section{BIBLIOGRAFÍA:}

Araguas, V. (2005) Maneiras de Querer. Obra poética (1978-2005), A Coruña, Espiral Maior.

Frías Conde, F. X. (2007) Poesía Gallega Contemporánea en Madrid. El grupo Bilbao, Madrid, Cuadernos del Ateneo, pp. 71-110. 